\title{
Logistic net working to reduce cost and environmental impact for urban cargo deliveries
}

\author{
D. Tacla ${ }^{1,3}$, R. C. Botter ${ }^{2}$, O. F. Lima Jr. ${ }^{3} \&$ S. Suyama ${ }^{1}$ \\ ${ }^{1}$ DHL Exel Supply Chain, Brazil \\ ${ }^{2}$ Universidade de São Paulo, \\ Escola Politécnica, Logistic and Transportation Area, Brazil \\ ${ }^{3}$ Universidade Estadual de Campinas, \\ Departamento de Geotecnia e Transportes, LALT, Brazil
}

\begin{abstract}
Cargo Delivery Operation in urban areas is a problem in all populous cities, and a critical problem in huge metropolitan areas. In the same way, if we think about central areas inside a commercial centre, it is a huge problem. The current prices of land in those areas can make it impossible to build adequate areas to receive large numbers of cargo vehicles, and to handle and unload cargo in commercial centers or malls. I addition, thousands of small and medium trucks circulating in the cities causes pollution, a lot more than necessary.

How to balance it? Is it possible to keep controlled and adequate costs involved in unloading cargo, and at the same time help save the environment? The target of this paper is to reduce logistic costs and the environmental impact: optimizing vehicles, urban area and labor (commercial or malls). A consolidation site, at the entrance regions of the cities (or more than one), can receive cargo from industries and/or any other suppliers in small trucks, then operating a cross docking, consolidate cargo, plan optimized routes, and finally ship to the final destination. The additional costs generated for this cross docking site operation will be compensated for by the shipper's last mile of transportation and reduced costs for receiving and handling the cargo by the final customer (a mall for example).

Non-planned logistics between shippers and receivers brings many more trucks than is reasonable; with them come more traffic, pollution, and other costs; this gap that we see frequently in the market provides an opportunity for this study that if implemented can provide a mitigation factor. Finally, this paper shows a numerical simulation with a real database to prove the proposal's study efficacy.
\end{abstract}

Keywords: logistic net working, cargo transportation, urban delivery, traffic, pollution, environment. 


\section{Introduction}

Transportation today is an issue that becomes more difficult to live within a big city; transporting cargo or people, or simply moving ourselves is expensive and takes a long part of our life.

People and cargo compete for the same space on the streets, and they compete for the same space at the stores, and compete for time.

Cargo must arrive at the stores before people, but not too much before. There is no space to store cargo in central stores; the area is too expensive for that, inventory is also expensive; but more expensive for the business is not having goods when and where the customer wants to buy them. Increasing stock storage facilities can mean having to reduce the space available for the customer parking area or even the shop floor. The problem however, starts even before cargo and customers arrive at commercial places. It starts with the transportation of goods far from the urban area.

\section{Problem characterization}

Cargo Delivery Operation in urban and especially central urban commercial centers is a huge problem. It is because products sourced in a "Global World".

The customer will not wait for a product that is delayed or whose supplier could not pay for transportation. Global networks must have an efficient local transportation solution. It is make no sense to have many small trucks trying to access shopping centers at the same time; competing with customers cars through over loaded streets. It means also more pollution.

Usually, the logistic planning is done by the goods seller; it means:

1- The store (buyer) orders goods based on his own forecast, inventory and available space;

2- The supplier receives the order and starts his production forecast, asks for parts and raw materials;

3- The supplier dispatches the order to his $3 \mathrm{PL}$ or to his retailer;

4- Goods are shipped to the store.

5- Thousands of small trucks are circulating right now inside the towns, a number of them to the same stores with same kind of products.

\section{Study proposal: using global logistics to save money and the environment}

The challenge is to find a balance between inventory cost, transportation cost and keeping the costs advantages coming from global producing system. The focus is to gain optimization through consolidation sites, with logistic intelligence, at the entrance region of the cities. They will receive cargo from industries and/or any other supplier, and then by operating a cross docking system, doing a pre planned to a larger truck, consolidating cargo, planning optimized routes, and finally shipping to a shopping center as the final destination, reduce system costs, reduce the environmental impact and improve people's quality of life. 
This idea will incur additional costs associated with the cross docking site and operation, but they should be offset by shipper last mile transportation and reduced costs for receiving and handling the cargo by final customer.

The concepts here, to support this proposal, are:

- Reduced transportation costs by reducing the number of trucks (lower fixed cost);

- $\quad$ Routing truck deliveries (lower variable costs);

- Cheaper areas at the city entrance used for cross docking sites, rather than expensive city centre areas.

- Environmental cost savings.

\section{Shopping centers as focal point}

A shopping center in a big city is more than a collection of stores, it is a concept of modern life; it concentrates huge numbers of people spending money and importantly part of their free time. Shopping centers were born in the USA in the middle of the 20th century, and now account for more than 50\% of retailers' sales. In Brazil, the country chosen for the application of this paper, there are about 970 malls, with 315 registered as Shopping Centers at the class entity (ABRASCE). The growth of this kind of business and these huge figures motivate this research and proposal. Sales are growing and represent the biggest part of the retail business in the big cities. Figure 1 shows the sales evolution of the shopping centers in Brazil (source: ABRASCE). Also important for this study is area that the shopping centers use for their facilities and stores. Figure 2 shows the area evolution of the shopping centers in Brazil (source: ABRASCE).

The land occupied by shopping centers normally represents the biggest asset and highest investment cost. In order to optimize this investment it is important to use the area for core business - serving the customer and generating revenue and profit.

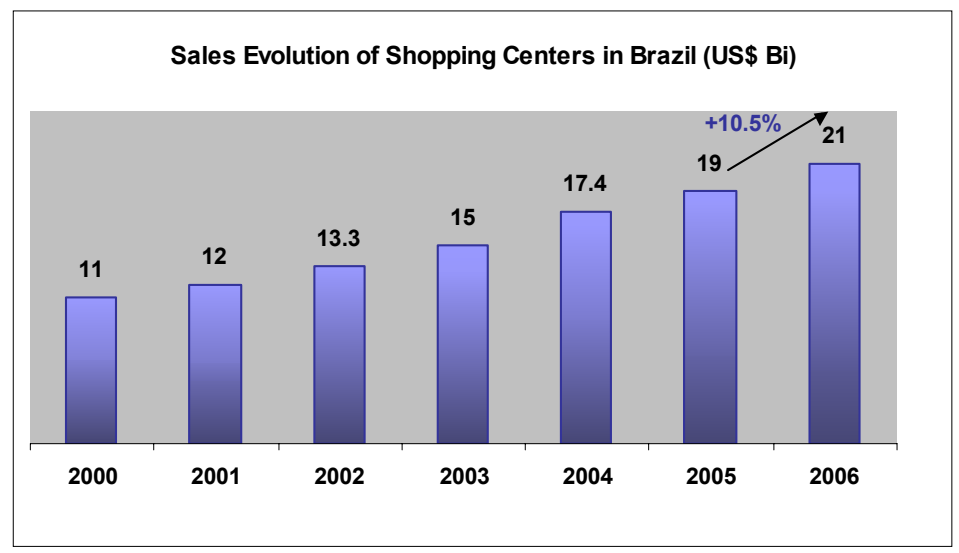

Figure 1: Sales evolution. 


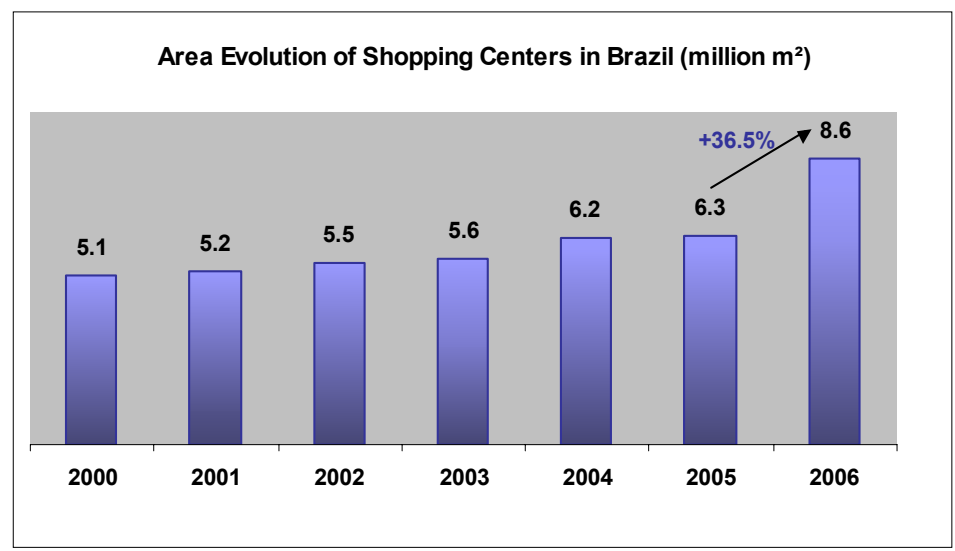

Figure 2: $\quad$ Area evolution at shopping centers.

This paper proposes the use of logistic net working to reduce the number of cargo vehicles in city centers and to decrease the need to use prime city locations to unload those vehicles, thereby reducing costs.

\section{Logistic net working design and proposal concepts applied shopping centers in urban areas}

Logistic Net Working can be defined as a set of "Supply Chains" that determines the flow of goods and services from origin to final customer, involving: side links; reverse flows; and flows with double direction. The concept is clearly different from simple supply chains, where the models are linear and with unique direction (Lamming et al [7]).

Transportation activity is the most important supply chain link in terms of complexity and cost; usually their issues or opportunities drive the design of the Net. It is very common for companies to plan Logistic Net Working based on their own necessity, and collaboration between shippers does not exist, and any kind of transport consolidation is operated by the carriers in charge of delivery. However, the carriers do not have the complete logistic view, not knowing what else the final customer needs to receive from other suppliers, and consequently from other carriers. In this context a third part logistic provider (3PL) can integrate and build a new chain, integrating one between carriers, shippers and customers.

This paper brings a proposal for the integration of different supply chains by a 3PL in a new Logistic Net Working oriented to the final destination, and therby reducing resources and energy in the logistic system.

Potential gains are greater and more apparent in urban transportation serving Shopping Centers, because:

- Large volumes and varieties of goods delivered to a concentrated place;

- $\quad$ The areas available to unload cargo are normally small and expensive; 
- The majority of the available workforce prefer to work in the store, not handling the cargo;

- Transporting cargo by large numbers of small trucks from several points is more expensive than transporting by bigger trucks from 3PLs Distribution Centers (DC).

It is necessary to plan Logistic Net Working from the end to the beginning, i.e. start with the final customer and work outwards.

A store in a central urban shopping center asks for goods to replace his short storage from several suppliers, and each of them makes his respective delivery plan by an isolated way; there is no collaborative plan, either between the various suppliers or through 3PL. The common net is: Shipper to DC to Carrier to Shopping center, or more simply: Shipper to Carrier to Shopping center. The paradigm is: adding a 3PL and/or a consolidation center will cost more and increase lead-time; it is not true.

The target must be a good plan starting from final customer; the general description of this model can be:

1. What and when does the final customer want to buy? With this answer the next question is:

2. When does the store need to receive based on normal storage? With this answer the next question is:

3. From the same kind of shippers, what set of products does the shopping center need to receive? With this answer the next question is:

4. What is the best plan in terms of time window, area and resources to receive the products?

With those questions answered the point is established with the focus on final customer, but planning from destination and not from origin as common; then, it is possible to re-design the Logistic Net Working starting from the begin now.

Searching for the answer as an isolated system would result in a conventional model with the goods flow. Re-designing the Logistic Net Working based on the proposal of this study means:

1. Keep the goods flow, with common carrier;

2. Add new suppliers with more cargo - compatible and with common destination;

3. Adjust the information flow to plan cargo consolidation;

4. Introduce a manager entity (3PL for example);

5. Locate 3PL site on City entrance.

The proposal is for the 3PL to concentrate and distribute the information (Planning and Operation information); and receive, consolidate and ship goods to final customer. With that is possible to optimize transportation and resources (customers and carriers resources). The location of the 3PL site to receive and consolidate cargo is an important part of this proposal. The concept of this study is to locate the site at a city entrance (or entrances if more than one site is used), allowing the 3PL to receive, consolidate and ship cargo from outside the urban area and to enter the city to deliver direct to the customer. 


\section{Numerical simulation with real database}

In the currently, shipments are made based on orders from factory to customer. There is no cargo optimization, or a cross docking point between factories and final destination, resulting in a large number of trucks for urban cargo deliveries.

The factories receive orders, ship to a DC or straight to customers; the most common logistic consists on cross the city to carrier's sites to consolidate the cargo with other shippers and to several customers in the same region of city, it means: the consolidation and routing trucks has the optimization of the deliveries per city region, and not the logistic plan; the problem is the amount of cargo per truck must attend the main constrain: capacity to delivery in the day. If the carrier tries to use a bigger truck putting more cargo than three or four deliveries the probability of fail is great. This is the problem: the carriers have the mission of consolidation and delivery optimization, but the cargo that should be with this carrier to complete this mission is with other one. It is like trying to complete a puzzle without all pieces, part of those pieces are spread out all over the city; they come from several shippers to common customers. Figure 3 represents the current situation, case: Sao Paulo, Brazil. The scenery of this study is characterized in generic lines, the normal way of Logistic Net Working to provide transportation to stores in the city, and with more focus here to shopping centers in to urban areas. To apply this proposal, the study brings a real database of important shippers (electronic and fashions goods) that use a 3PL to storage and transport, but not to plan.

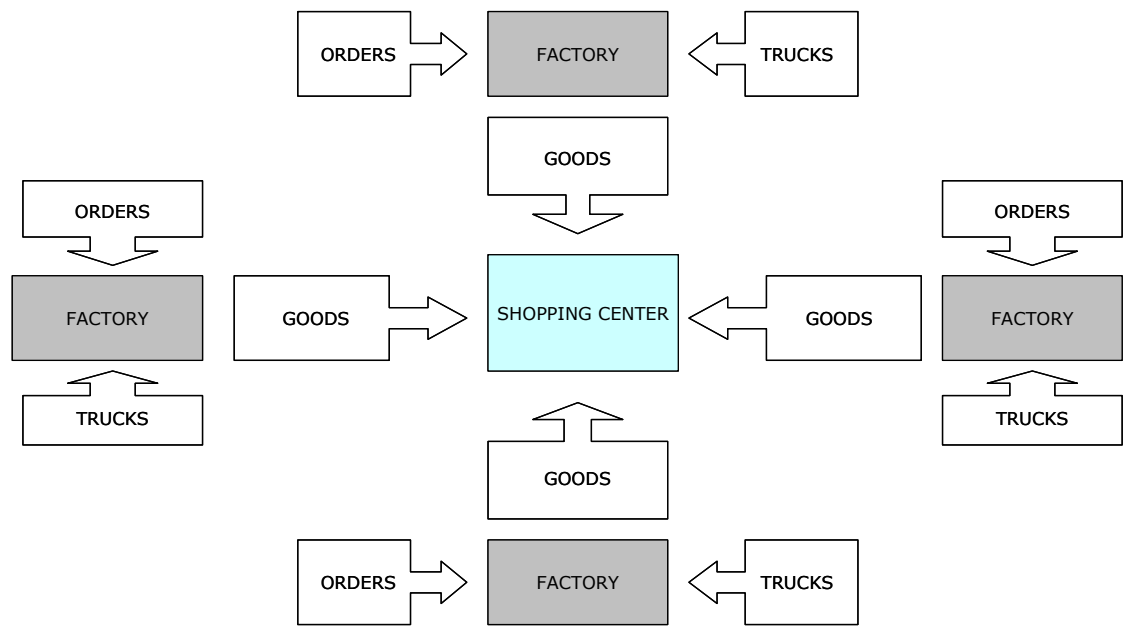

Figure 3: Current situation - The plan is made as an isolated entity and with no customer participation or collaboration. 
Based on the final destination, we proposed a consolidation site in order to reduce the amount of vehicles by routing truck deliveries, and consequently saving environmental costs. Figure 4 illustrates our proposal.

In order to simulate cargo consolidation, we used Microsoft Excel Pivot Table, setting type of vehicles according to their capacity.

As proposed in this study, the simulation in real database planned Shopping Centers deliveries, respecting the service level agreement and the lead time requested; basically the vehicles were dispatched and routed based on customers (destination and goods requested).

Figure 5 represents the study scenery. The results are showed in Figure 6. The numbers of visits to the 14 shopping centers decreased by $51 \%$, in a monthly period (December, 2006) the number of deliveries in the 14 shopping centers decreased from 578 from 278 deliveries. The most impressive result was the reduction vehicle numbers by $83 \%$, from 273 to 47 . Freight cost was reduced by $33 \%$ comparing historical data.

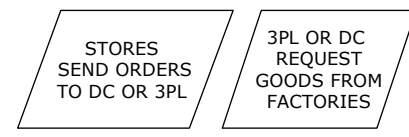

Figure 4: Information and goods flow.
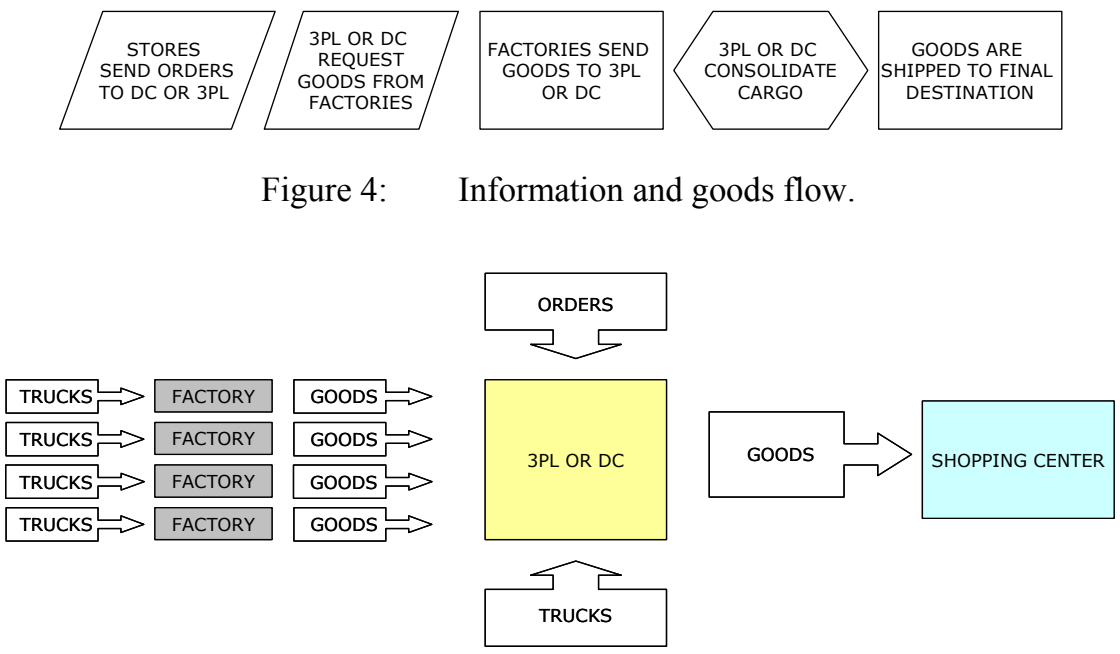

Figure 5: $\quad$ Study scenery.

\section{Conclusion}

The study reached the target, the proposal reduced freight by $33 \%$ and the number of vehicles used was reduced by $83 \%$. Figure 6 shows a result summary.

In terms of land it is possible to conclude that is viable to reduce the amount of space needed for cargo handling by about $50 \%$, because the paper showed a reduction of $51 \%$ of shopping center deliveries; the relation between deliveries and unload area is direct.

The amount of pollution certainly would greatly decrease if this proposal were applied, and in the same way the quality of life in urban areas would increase, with decreased traffic. 


\begin{tabular}{|l|r|r|}
\hline Monthly Scenery & Current & Proposed \\
\hline Cargo Value (US\$) & $\$ 2.195 .054,55$ & $\$ 2.195 .054,55$ \\
| Loaded Weight (kg) & $62.859,45 \mid$ & $62.859,45$ \\
| Destinations & $14 \mid$ & 14 \\
| Shipment points & 4 & $1 \mid$ \\
| Deliveries & $568 \mid$ & $278 \mid$ \\
| Number of vehicles & $273 \mid$ & 47 \\
Total freight (US\$) & $\$ 11.093,73 \mid$ & $7.382,85$ \\
\hline
\end{tabular}

Figure 6: Results summary.

Table 1: $\quad$ Comparison between real and study proposed.

\begin{tabular}{l|cr|rr|rr}
\hline \multirow{2}{*}{ Delivery Date } & \multicolumn{2}{|c|}{ Current } & \multicolumn{2}{c|}{ Proposed } & \multicolumn{2}{c}{ Results } \\
\cline { 2 - 7 } & $\begin{array}{c}\# \\
\text { Vehicles }\end{array}$ & $\begin{array}{c}\text { Total Freight } \\
\text { (US\$) }\end{array}$ & $\begin{array}{c}\# \\
\text { Vehicles }\end{array}$ & $\begin{array}{c}\text { Total Freight } \\
\text { (US } \$)\end{array}$ & $\begin{array}{c}\# \\
\text { Vehicles }\end{array}$ & $\begin{array}{c}\text { Freight (\%) } \\
\text { Vreigh }\end{array}$ \\
\hline Dec, 1st & 24 & 997.19 & 3 & 471.86 & $-88 \%$ & $-53 \%$ \\
Dec, 2nd & 1 & 117.62 & 1 & 132.95 & $0 \%$ & $13 \%$ \\
Dec, 3rd & 2 & 408.38 & 3 & 396.79 & $50 \%$ & $-3 \%$ \\
Dec, 4th & 9 & 428.85 & 2 & 300.27 & $-78 \%$ & $-30 \%$ \\
Dec, 5th & 10 & 221.30 & 2 & 353.89 & $-80 \%$ & $60 \%$ \\
Dec, 6th & 12 & 272.16 & 1 & 225.21 & $-92 \%$ & $-17 \%$ \\
Dec, 7th & 14 & 383.05 & 2 & 364.62 & $-86 \%$ & $-5 \%$ \\
Dec, 8th & 13 & 303.73 & 2 & 343.17 & $-85 \%$ & $13 \%$ \\
Dec, 9th & 2 & 690.51 & 3 & 471.86 & $50 \%$ & $-32 \%$ \\
Dec, 10th & 1 & 474.30 & 2 & 311.00 & $100 \%$ & $-34 \%$ \\
Dec, 11th & 35 & 987.94 & 3 & 471.86 & $-91 \%$ & $-52 \%$ \\
Dec, 12th & 21 & 473.36 & 2 & 353.89 & $-90 \%$ & $-25 \%$ \\
Dec, 13th & 18 & 767.91 & 1 & 246.65 & $-94 \%$ & $-68 \%$ \\
Dec, 14th & 21 & 621.97 & 2 & 353.89 & $-90 \%$ & $-43 \%$ \\
Dec, 15th & 19 & 698.33 & 3 & 471.86 & $-84 \%$ & $-32 \%$ \\
Dec, 16th & 2 & 812.25 & 2 & 364.62 & $0 \%$ & $-55 \%$ \\
Dec, 17th & 1 & 505.31 & 1 & 225.21 & $0 \%$ & $-55 \%$ \\
Dec, 18th & 19 & 890.86 & 2 & 353.89 & $-89 \%$ & $-60 \%$ \\
Dec, 19th & 20 & 525.80 & 1 & 246.65 & $-95 \%$ & $-53 \%$ \\
Dec, 20th & 13 & 373.42 & 2 & 353.89 & $-85 \%$ & $-5 \%$ \\
Dec, 21st & 5 & 142.78 & 1 & 225.21 & $-80 \%$ & $58 \%$ \\
Dec, 22nd & 3 & 46.13 & 1 & 90.97 & $-67 \%$ & $97 \%$ \\
Dec, 23rd & 1 & 72.11 & 1 & 104.96 & $0 \%$ & $46 \%$ \\
Dec, 26th & 2 & 23.00 & 1 & 62.98 & $-50 \%$ & $174 \%$ \\
Dec, 27th & 1 & 7.38 & 1 & 62.98 & $0 \%$ & $754 \%$ \\
Dec, 28th & 2 & 93.60 & 1 & 104.96 & $-50 \%$ & $12 \%$ \\
Dec, 29th & 2 & 72.96 & 1 & 128.69 & $-50 \%$ & $76 \%$ \\
\hline Total & 273 & $11,412.21$ & 47 & $7,594.80$ & $-83 \%$ & $-33 \%$ \\
\hline & & & & & &
\end{tabular}


Collaboration and planning - they are enough to reduce freight and environmental costs in urban areas, when delivering cargo to Shopping Centers.

\section{References}

[1] ABRASCE, Associação Brasileira de Shopping Centers, http://www.abrasce.com.br/ind_shopping/estatisticas.htm.

[2] Bowersox D.J. \& Closs, D.J., Logistical Management: The Integrated Supply Process. McGraw-Hill. USA, 1996.

[3] Browning, B. \& White, A., Collaborative Transportation Management - A Proposal, USA, 2001.

[4] Desrochers, J., Soumis, F. \& Belanger, N., Ioachim., Fleet Assignment and Routing With Schedule Synchronization Constraints, I. European Journal of Operation Research, 119, Elsevier Science, 1999.

[5] Gorham, R. Air pollution from ground transportation: an assessment of causes, strategies and tactics, and proposed actions for the international community. Department of Economic and Social Affairs, United Nations, 2002.

[6] Hirschfeldt, R.V., Shopping Center: o templo do consumo. Rio de Janeiro, ABRASCE, 1986.

[7] Lamming, R. et al., An initial classification of supply networks, International Journal of Operations \& Production Management, 20(6), pp. 675-691, EUA, 2000.

[8] Lima Jr., O.F., A Carga na Cidade: Hoje e Amanhã, LALT Universidade Estadual de Campinas, 2005.

[9] Story, D.W., ICSC Keys to shopping center management series and security process, New York, ICSC, 1992.

[10] Tacla, D. \& Botter, R., Study of Collaboration Transportation of large volumes of bulk cargoes, with application in case of soy and fertilizers, White paper, 2003. 